\title{
SOCIENTIZE participatory experiments, dissemination and networking activities in perspective
}

CÂNDIDA G. SILVA, RUI M. M. BRITO Coimbra Chemistry Centre, Department of Chemistry, University of Coimbra, 3004-535 Coimbra, Portugal; Centre for Neuroscience and Cell Biology, University of Coimbra, Coimbra, Portugal

ANTÓNIO MONTEIRO, Department of Chemistry, University of Coimbra, 3004-535 Coimbra, Portugal

JOSÉ A. FARIAS LEAL, ADABRIAND FURTADO, NAZARENO ANDRADE, FRANCISCO BRASILEIRO, Systems and Computation Department, Federal University of Campina Grande, Campina Grande, Brazil

PAULO GAMA MOTA, Science Museum of the University of Coimbra, Coimbra, Portugal

CAROLINE MANAHL, TERESA HOLOCHER-ERTL, ZSI, Centre for Social Innovation, Vienna, Austria

MANUEL PÉREZ ALCONCHEL, Tecnara, Plaza del Pilar 16, Zaragoza

EDUARDO LOSTAL LANZA, CARLOS VAL GASCÓN, FRANCISCO SANZ, FERMÍN SERRANO SANZ, Institute for Biocomputation and Physics of Complex Systems, Zaragoza, University of Zaragoza

\begin{abstract}
Citizen Science, a fairly new term but a practice with more than a century, includes today a wide range of activities through which citizens may play a central role in scientific projects, either by collecting data, analyzing massive data sets, providing resources, or by developing small-scale experimental activities among grass-roots groups. In parallel, the realm of Digital Society is upon us, triggering a social and information revolution. Today, large computing infrastructures and high performance communication technologies allow the tackling of up till now intractable scientific problems, in a new field known as e-science supported by e-infrastructures. Similarly, the millions of people around the world that are permanently interconnected through their
\end{abstract}


computers and mobile devices, may be considered as a citizen-based infrastructure (cinfrastructure) to perform c-science through distributed computing, collective talent exploitation, and ubiquitous data gathering. Funded by the European Commission, SOCIENTIZE is a Seventh Framework Programme project that aims to set the basis of citizen science in Europe for Horizon2020. For the last two years, SOCIENTIZE has been promoting Citizen Science to: (1) raise awareness about the importance and impact of citizen science, (2) foster interaction and coordination between all citizen-science actors, (3) promote the capabilities of c-infrastructures among researchers and citizens for an enhanced science, (4) coordinate and promote citizen science projects, and (5) collect and share best practices and recommendations for the implementation of citizen science projects in Europe. To achieve these goals, SOCIENTIZE has developed and implemented several citizen cyberscience activities that are described herein.

\section{INTRODUCTION}

Citizen Science is today understood as the engagement of the general public in scientific research activities, with citizens actively contributing to science projects either with their intellectual effort or knowledge or with their tools and resources. Based on scientific volunteering, citizen science projects raise awareness within communities about the importance of research, and equally important, develop critical thinking skills, fundamental for any decision-making process. Several models of citizen participation in research projects have been proposed from basic top-down approaches where citizen science projects are initiated by scientists that involve non-scientists in different tasks such as data collection and analysis (Cohn, 2008; Bonney, 2009) to projects in which researchers immerse themselves into local communities to closely collaborate with local actors and citizens, identify research questions, and provide their scientific skills in order to solve relevant issues of today's society (Mueller, 2012; Hacklay, 2013). In the last few decades, citizen science experienced considerable expansion fueled by the development of sophisticated Internet applications that effectively utilize crowd-sourcing for data collection over large geographic regions (Dickinson, 2010). At the same time, advances in data storage and web technology are making the increasing amount of collected data, including images and audio(-visual) files, easier for volunteers to access. Social networking technologies such as forums and blogs are allowing communities to form around a shared interest in scientific research (Raddick, 2009; Shirk, 2012; Wiggins \& Crowston, 2011).

Most of the participatory citizen science projects described in the literature are based in the US and UK, however within the EU there is a growing awareness for the potential of citizen science projects, reflected in the number of new citizen science initiatives funded by the Seventh Framework Programme (FP7) for Research (Science Communication Unit, 2013). SOCIENTIZE, acronym for "Society as e-Infrastructure through technology, innovation and creativity", is one of such examples. 
SOCIENTIZE (http://www.socientize.eu) is a FP7 project aiming to set the basis of citizen science in the European context, by coordinating all agents involved in the Citizen Science process in Europe. The SOCIENTIZE consortium consists of five institutions in four different countries plus an External Advisory Board. The project promotes the use of scientific infrastructures composed by dedicated and external resources, including professional and amateur scientists, while it supports a network where infrastructure providers and researchers can recruit volunteers from the general public to perform science at home or in schools. Furthermore, SOCIENTIZE is working on the compilation and sharing of best practices, oriented towards research infrastructure users and providers as well as policy-makers as recommendations for implementing citizen science projects. To accomplish these goals, the SOCIENTIZE consortium is working along three major lines of action: (i) implementation of citizen science projects; (ii) dissemination activities with different target groups; and (iii) network activities with major European stakeholders on citizen science. One of the main outcomes of the project was a White Paper on Citizen Science, compiling the experiences from diverse stakeholders involved in citizen science (e.g., volunteers, researchers, infrastructure providers, scientific organizations, communicators, innovators, journalists, educational experts, artists). This document should set the basis for future deployment of experiments and inform policy makers when setting up future strategies for citizen engagement in science of excellence. Here, the consortium reports the results on its activities in particular to the citizen science applications developed, dissemination approaches, and networking activities.

The remainder of the paper is structured as follows. First, a general description of the SOCIENTIZE infrastructure is provided. Next, the citizen science applications developed are presented. In section 4 , the dissemination approaches promoted by the consortium are presented and the networking activities are described in section 5. Section 6 includes the general conclusion of SOCIENTIZE work.

\section{SOCIENTIZE C-INFRASTRUCTURE}

Generally, e-infrastructure is defined as the technology and organization that supports research undertaken through distributed regional, national and global collaborations enabled by the Internet dealing with large data collections, advanced ICT tools for data analysis, large-scale computing resources, and high-performance visualization. The SOCIENTIZE project seeks to widen the understanding of the digital society as another e-infrastructure itself. We call cinfrastructure any e-infrastructure that requires citizen participation to perform the scientific work. That participation may require different skills, from advanced knowledge to very simple tasks. In this scenario, the human brain and time may be considered as resources of the einfrastructure. The infrastructure can be also composed of external distributed resources, like desktop computers, smart phones or any scientific device that people can provide (thermometers, cameras and so on) to collect and/or analyze scientific data. c-Infrastructures are linked bi- 
directionally to people, ensuring effective dissemination of goals and results, and allowing openaccess or management for some of the features.

The SOCIENTIZE c-infrastructure encompasses a complex system of ICT-based resources and services that can be used by scientific researchers directly open to the public. Dedicated servers are deployed and managed in the project partners' internal facilities and connected to other external devices and repositories. Rather than developing a technology from scratch, the consortium opted to analyze existing technologies and resources, in particular open-source tools, selecting and integrating those technologies that provide better solutions to support scientific experiments as well as to find the most effective way to attract volunteers not only to help professional scientists to solve problems, but also to let the general public propose and create experiments. Major technological components are related to system administration, web and mailing list support, database management, and citizen science applications middleware. Currently, PyBossa (http://crowdcrafting.org) and Epiwork (http://www.epiwork.eu) are SOCIENTIZE main middleware components for citizen science applications deployment.

PyBossa is an open source platform for crowd-sourcing online (volunteer) assistance to perform tasks that require human cognition, knowledge or intelligence (e.g. image classification, transcription, information location, etc). It can be used for any distributed task application but was initially developed to help scientists and other researcher's crowd-source human problemsolving skills. At this moment, PyBossa is one of the most important software components of SOCIENTIZE c-infrastructure. The consortium has contributed to the improvement of PyBossa features by providing the means to integrate it with Facebook, making possible its applications to run inside Facebook's interface.

The Epiwork framework, an outcome of the Epiwork project, is a web application for the generation and management of forms used for data collection. It provides tools to easily create, deploy, and manage surveys where users can enter data gathered. Although it was originally developed addressing epidemic forecast issues, it can be modified and used in similar projects. Epiwork is built on top of Django. Django is a high-level web application framework, written in Python, which follows the model-view-controller architectural pattern. Its primary goal is to ease the creation of complex, database-driven websites encouraging rapid development and clean, pragmatic design.

\section{SOCIENTIZE CITIZEN SCIENCE APPLICATIONS}

SOCIENTIZE is implementing a set of applications enabling volunteers to become scientists and showing the capabilities of open resources. Currently, four applications are included in the project portfolio ranging from molecular and cell biology and drug discovery (Cell Spotting), to linguistics and semantics (Mind Paths), energy saving and sustainability (SavingEnergy@Home), and astronomy (Sun4All). Two additional citizen science applications were subcontracted and included in the project's experiments portfolio. 


\subsection{Cell Spotting}

The identification of drugs capable of inducing the death of tumor cell is one of the major lines of research in cancer. An approach could be searching for chemical compounds capable of inducing tumor cells death, and among those drugs found, select ones that do not induce death of healthy cells. There are two major types of cell death: apoptosis and necrosis. Apoptosis is a type of programmed cell death, physiologically controlled, that eliminates cells in a silent manner. On the other end, necrosis causes an inflammatory response due to cell content release that can damage surrounding tissue. Ideally, selected drugs should induce cell death by apoptosis. A similar successful approach has been used with stem cells, which in some aspects resemble tumor cells (Conesa, 2012).

These two types of cell death can be easily differentiated by microscopy in cultured cells. Advanced optical microscopy techniques allow cells to be cultured directly over the microscope in multiwell plates. Cell cultures in each well are subjected to different chemical compounds and photographed every half hour with appropriate filter for two fluorescence colors and in bright field, obtaining three different images of the same field at each time point, in four different positions of the well (Lostal, 2013a, 2013b). A single experiment produces 14,112 images. The different images obtained in each field at each time point are overlaid (bright field, blue and green fluorescence) to obtain a combined image, and are assembled chronologically to generate videos that show cell movements, cell division and cell death, allowing the observation of what happens over time.

The analysis of the thousands of images obtained includes classification of the cells according to several parameters like cell status, cell content release, mitochondria distribution or nucleus' shape. However, given that individual researchers cannot analyze the huge amount of generated data, the optimal approach would be to employ automatic computer image analysis techniques in a high performance distributed infrastructure. Unfortunately, computers are not as good as human brains concerning pattern recognition, and the classification of the described parameters, which might be difficult for humans, becomes harder for computers without extensive training (Lostal, 2013a, 2013b).

The development of the citizen science application "Cell Spotting" allows citizens to tackle the two problems discussed. First, citizen participation in the analysis of these large data sets provides an amount of analyzed results that would be unattained otherwise. On the other hand, the results intrinsically mean the creation of a large set of trainings that can be used for machine learning techniques, enabling the automatic analysis of the future cell culture images. 


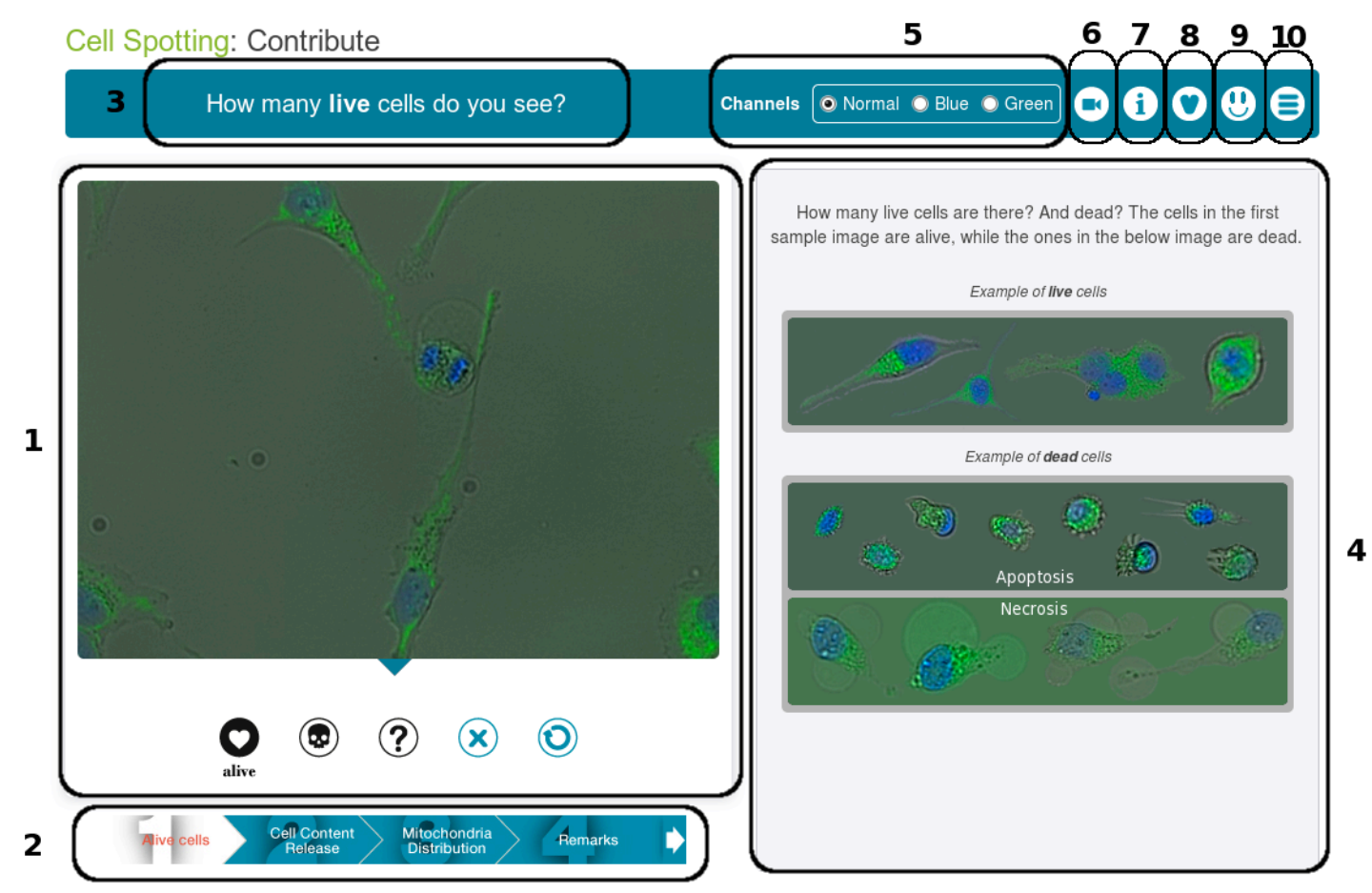

Figure 1. The Cell Spotting application. Volunteers are asked to classify large sets of images of cancer cells. In the search for new and effective drugs, these cells were treated with a drug sample. Via the Internet, citizens receive images of cell cultures being studied under a microscope (Box 1) and help to determine the actual state of each cell based on the answer to simple questions (Boxes 2 and 3). Multiple tools and tutorials are offered to perform the task and to evaluate the application (Boxes 5 to 10).

A Cell Spotting task encompasses the analysis of four parameters described above: current cell status (death or alive), cell content release, mitochondria distribution and other remarks (multinucleated cell, abnormal sized cells and nuclei, etc.). When accessing the application, a single image is presented (Figure 1, Box 1). To ease the task, each parameter is analyzed in a different step (Figure 1, Box 2) with the question identified on the top bar (Figure 1, Box 3). To assist the volunteer on the classification of each parameter, examples of the patterns that need to be identified are shown side-by-side with the image under analysis (Figure 1, Box 4). Further information on each step is available on the top bar (Figure 1, Box 7). The top bar incorporates additional resources to ease the analysis process. The volunteer may alternate between the images channels: blue to visualize just the nucleus, green to view just the mitochondria, and normal shows the three main constituents of the cell: membrane, nucleus and mitochondria (Figure 1, Box 5). The volunteer may also view the image under analysis in the context of the experiment (Figure 1, Box 6). 
To support and enrich the experience of the citizens participating with Cell Spotting, different training materials have been prepared including didactic unit (Figure 1, Box 10), and a virtual excursion room, where schools are able to experience the work at the cell laboratory (Figure 1, Box 8). This virtual excursion is made available via the GLOBAL Virtual Science Hub "ViSH". ViSH contains a selection of e-Infrastructures and science-teaching related material accessible via a collaborative content repository for teachers and scientists to exchange and establish collaborations. ViSH has been developed within the Global Excursion project1 that aims to introduce e-Infrastructures to science teaching in European schools.

Another important aspect to the SOCIENTIZE consortium is the continuous evaluation of the applications developed, in particular regarding what concerns the volunteer experiences. For evaluation, volunteers can at any time fill out a questionnaire (Figure 1, Box 9) that helps researchers better understand the impact of volunteers' involvement and removes potential barriers that might make the participation of citizens in research projects difficult.

Cell Spotting has been developed in collaboration with the "Stem cells and Apoptosis Group" from the Institute for Biocomputation and Physics of Complex Systems (BIFI) of the University of Zaragoza (Spain), and it is available at http://cellspotting.socientize.eu.

\subsection{Mind Paths}

The Mind Paths application is related to research in the areas of language complexity and dynamics, and semantics. These studies are relevant not only to understand the cognitive mechanisms underlying language usage, but also interesting in relation to search engines or neuromarketing, among others.

Since the work by Quillian in the late ' $60 \mathrm{~s}$, the view of semantic memory as a networked structure has provided a valuable collection of scientific results (Quillian, 1967, 1968). As the scientific community has learned what such network looks like (e.g. their structural features), interest has shifted to understanding how this structure is used (e.g., the dynamics of it). Of course, processes on semantic networks can be (and have been) simulated via "synthetic" dynamics, such as random walks (Borge-Holthoefer and Arenas, 2010). But there is few empirical evidence of how humans actually navigate their "semantic landscape".

This is where citizen science comes in. Capitalizing on a previous, small-scale experiment (Beckage, 2011), the Mind Paths experiment intends to collect data from subjects around the world regarding their strategies to navigate a semantic landscape. In Mind Paths (Figure 2), for a given Source and a Target, volunteers are asked to build a path of intermediate words that connect them. In the long run, the obtained data will help scholars understand what sort of heuristics we exploit to efficiently manage our intricate structure of concepts.

\footnotetext{
${ }^{1}$ http://www.globalexcursion-project.eu
} 


\section{Mind Paths: Contribute}

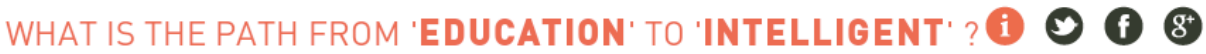
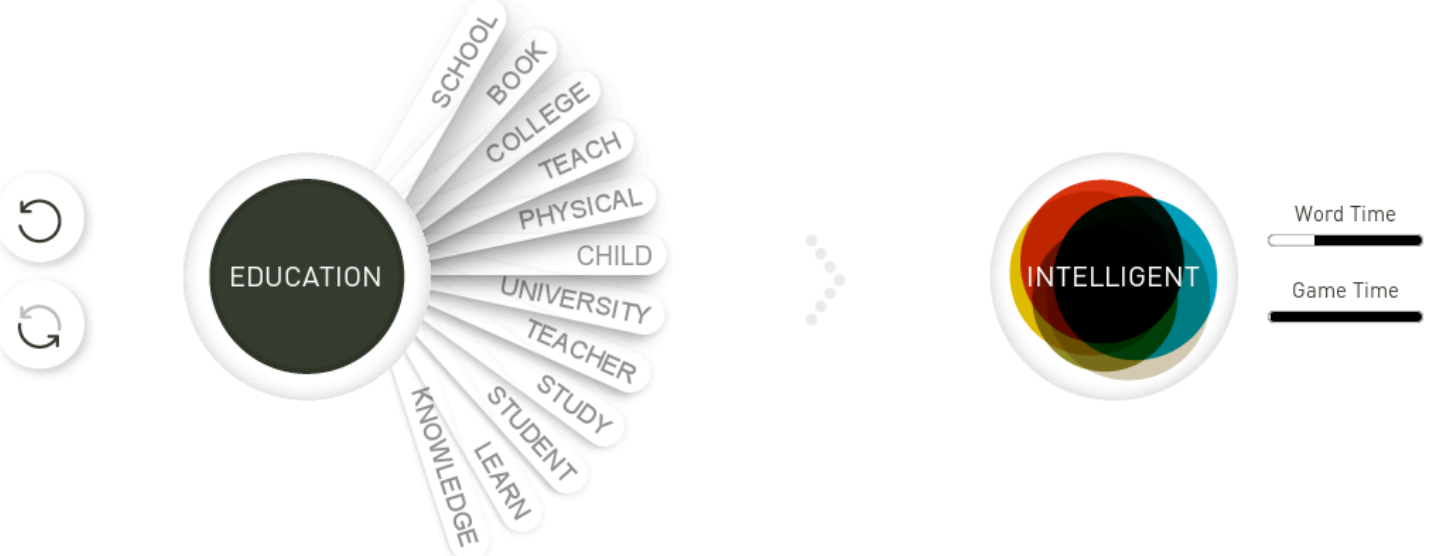

Figure 2. The Mind Paths application. The application is presented in the form of a game. Players are given a start location (starting word) in a semantic network and asked to build chains of associates to get to a target location (target word). There is a time limit to choose the next word in the path (Word Time) and for the construction of a path (Game Time).

The Mind Paths application is presented in the form of a game (Figure 2). As a starting point, we present a minimally biased version of the game. Citizens are given a start location (starting word) in a semantic network and asked to build chains of associates to get to a target location (target word). This data provides us with the decisions of individuals, which can deepen our understanding of the underlying navigation process and semantic environment.

Given the playful nature of the Mind Paths experiment, the consortium decided to explore the role of existing social networks for the recruitment of new volunteers in citizen science applications. The scientific applications that are developed in a gaming scenario allow volunteers to share the scores and ranking profiles with connections in their social networks. We believe that the integration of citizen science platforms with social network environments may also boost the projects' visibility.

Mind Paths has been developed in collaboration with the Complex Systems and Networks Lab (COSNET) of the Institute for Biocomputation and Physics of Complex Systems (BIFI) of the 
University of Zaragoza (Spain), and it is available at http://mindpaths.socientize.eu and https://apps.facebook.com/mindpaths/.

\subsection{SavingEnergy@Home}

SavingEnergy@home is a citizen science project related to the optimization of energy consumption and environmental sustainability in public buildings and private homes. This project collaborates directly with volunteers to increase awareness and motivation on energy saving, while it allows researchers to perform sociological studies about the role that individuals play in the overall energy consumption of buildings.
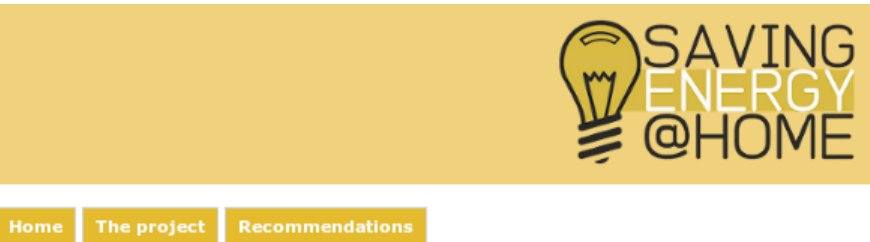

\section{Welcome to SavingEnergy@home!}

SavingEnergy@home is an online tool whose main goal is to monitor energy consumption at home, through selfless and anonymous collaboration of volunteers via Internet.

The aim of the project is twofold:

- On one hand, gathered data will allow researchers keep going on learning about factors that cause home energy consumption and the most effective saving measures.

- On the other hand, the project will bring an information and interaction tool enabling participants to know how much energy their homes consume according to the homes' characteristics and inhabitant's daily habits. Participants are able to analyse their own consumption in comparison to the rest of participants and the expected one according to their building characteristics. Customized tips for energy saving are provided.

Therefore, participants not only may improve the energy consumption and home efficiency, they get involved in the scientific process providing valuable information for researchers on sustainable building.
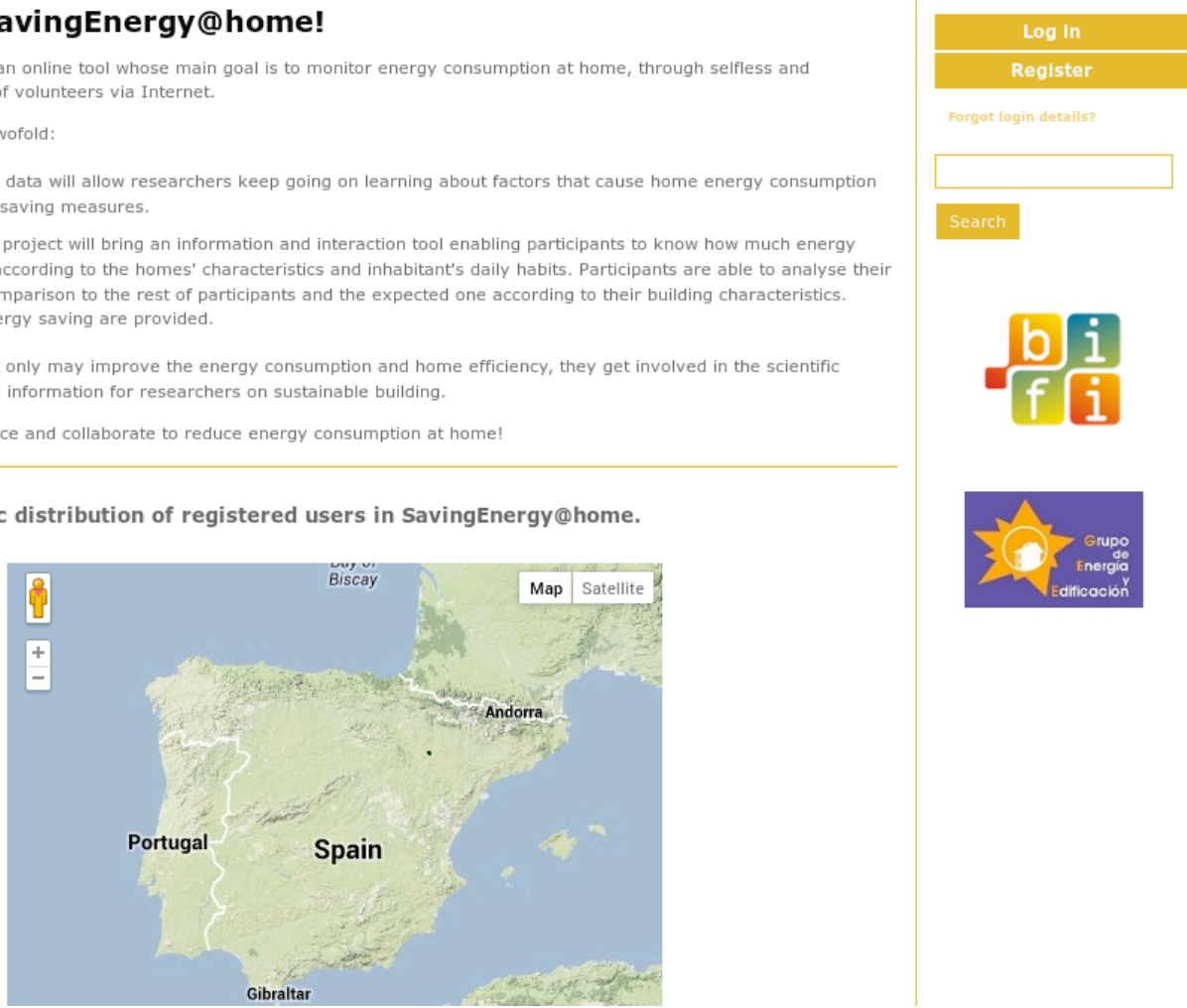

Figure 3. The SavingEnergy@Home application. Volunteers are invited to register and provide data that will be used to provide tips for the optimization of energy consumption and environmental sustainability in public buildings and private homes. 
Citizens participating in the project are invited to register and provide information on characteristics of their home, energy consumption habits, etc. (Figure 3). The answer to these questions helps scientists understand the efficiency in energy consumption and is the basis to provide every participant with further energy saving recommendations. The data on these questions can be visualized and updated whenever the volunteer feels it is necessary. Based on the information supplied, the participant will know what is the energy saving potential according to the characteristics of his/her home and/or other participants, whether his/her habits are effective and how to modify them to achieve energy saving at home. At any time, data about monthly energy consumption can be added and data on the house updated if there has been any significant change(s). Therefore, the participant's energy profile and recommendations will be updated according to consumption data and habits provided.

SavingEnergy@home is a platform developed by a team of researchers of the Institute for Biocomputation and Physics of Complex Systems (BIFI) and the Building and Energy Group (GEE), and it is available at http://savingenergy.socientize.eu.

\subsection{Sun4All}

The Sun is the Earth's main source of heat and light essential to all the life it holds. The phenomena that occur (occurred or will occur) inside the Sun and on its surface impact the Earth's surface. The solar surface irradiation is one of the measurable impacts of the Sun on Earth. It is especially regulated by what happens on the Sun's atmosphere. There are several phenomena that flow from the solar atmosphere, such as prominences or sunspots. Sunspots are temporary phenomena that, in a photo in positive, appear visibly as dark spots compared to surrounding regions.

The analysis and counting of sunspots is a very important aspect of the study of the phenomena occurring on the surface of the Sun and to understand the solar activity and solar cycle. Furthermore, studying the sunspots, besides being interesting itself, presents an important tool to understand much of what happens on the Earth climate. The Sun4All is based on an asset of over 30,000 images of the Sun - called spectroheliograms - that are kept at the Astronomical Observatory of the University of Coimbra, as result of a work of over 85 years of daily solar observations, started in 1926.

In Sun4All, the volunteers will find an image of the sun - a spectroheliogram - dated with the day when it was taken (Figure 4). The one used in this example was taken in March 6, 1995 (see above the picture). The objective is to count sunspots and sunspots groups. When a volunteer accesses the application a tutorial is presented explaining what are sunspots and groups of sunspots, and how the application can be used to mark the observations of interest. To facilitate the task, volunteers are provided with tools to manipulate the image such as zooming, moving the image, and inverting the image between the positive and negative filter. With the positive filter, sunspots appear as white spots while with the negative filter sunspots appear in black and are more easily identified. The buttons in the "Observation" box are used to add sunspots and sunspot 
groups, remove wrongly marked observations and add any other information the volunteer may find relevant. To add a sunspot, the volunteer just needs to click on the button "Add Sunspot", and then click on the sunspot observed in the spectroheliogram. Upon being clicked, a sunspot is marked with a yellow cross. The procedure to mark sunspot groups is similar: the volunteer clicks on the button "Add Sunspot Group", and then with the mouse draws a square around a group of sunspots observed in the spectroheliogram. The counting of the observations is done automatically and it is resumed in the "Your Data" box as the volunteer adds observations to the spectroheliogram. Once the analysis is completed, the volunteer can submit the results by clicking on the "Finish the task" button. The volunteer may also decide to "Start over" his/her analysis.

Sun4All has been developed in collaboration with the Astronomical Observatory of the University of Coimbra, and it is available at http://sun4all.socientize.eu.

\section{Sun4All}

This is an image taken in March, 6 - 1995

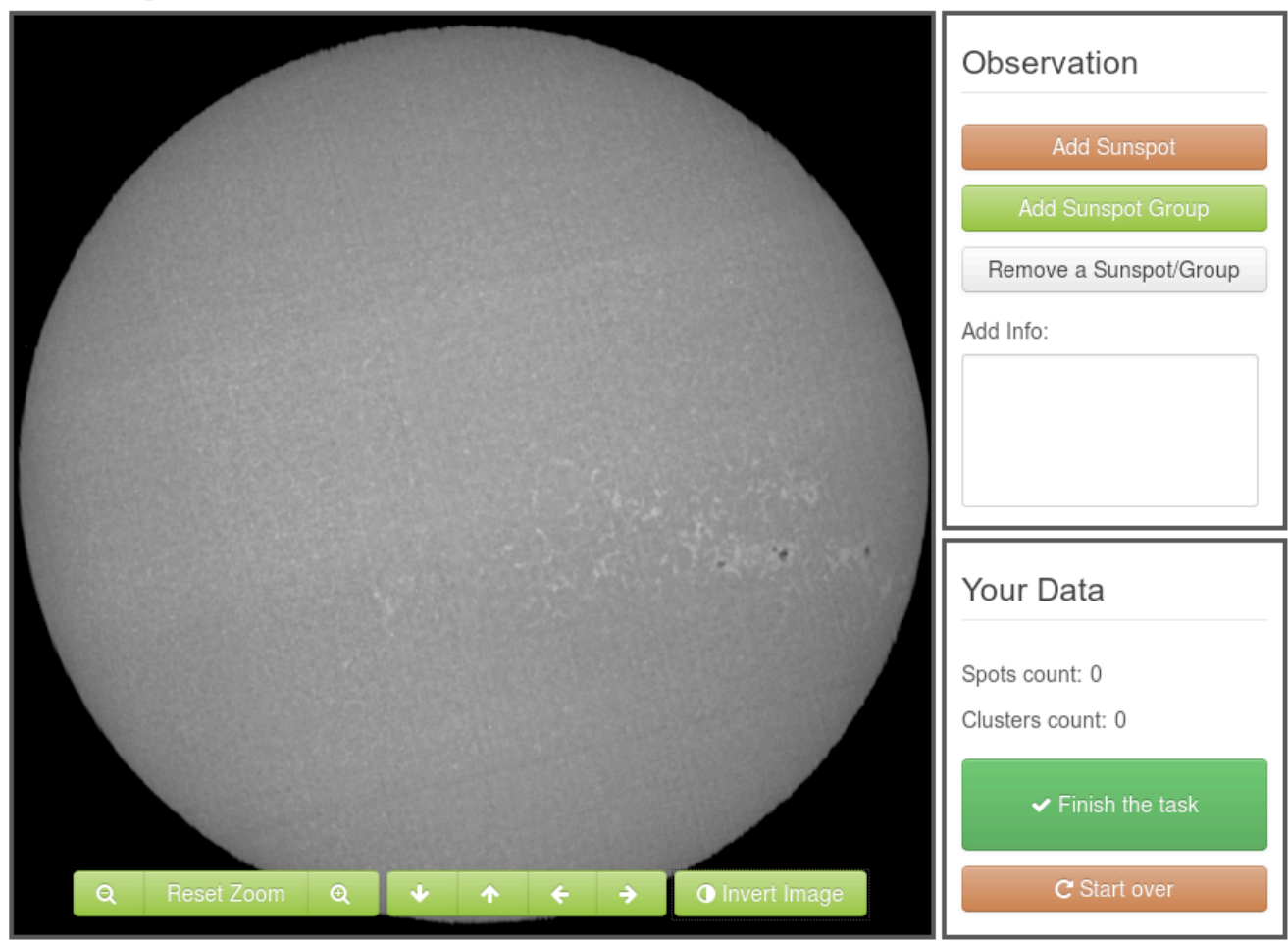

Figure 4. The Sun4All application. Volunteers are invited to analyze images of the Sun (spectroheliograms) by counting the number of sunspots and sunspots groups. 


\subsection{Subcontracted Applications}

To increase the impact of the SOCIENTIZE project through new user communities, technologies, scientific results, or learning experiences, two additional applications were subcontracted. A public call was launched (open to both academic and industrial organizations) seeking any kind of participatory experiment requiring large volunteer participation using ICT tools such as volunteer computing, volunteer sensing, or volunteer thinking. A total of 15 proposals were received from institutions in different European countries and the US, and covering a wide range of scientific areas. The consortium and the External Advisory Board members evaluated the contributions based on their scientific, social and technological interest for the project. The two selected proposals were Urban Bees (University of Barcelona, Barcelona, Spain) and AntiMatter (CERN European Organization for Nuclear Research, Geneva, Switzerland).

The Urban Bees project aims to increase public awareness to the importance of bees for human sustainability. Involving a cross-disciplinary community (urban beekeepers, artists, cultural managers, biologists, data scientists, physicists, engineers) and opened to citizens in general, the project objective is to build beehives coupled with sensors capable of analyzing the quality of pollen and propolis as well as the behavior of bees to monitor the surrounding urban area ecosystem. These intelligent beehives will be placed in public areas of different European cities that will enable researchers to gather data from diverse bees' urban ecosystems. Sensors are configured using open source software compatible with Arduino components.

AntiMatter is a citizen science application to help the AEgIS experiment at CERN to understand how antimatter is affected by gravity. The AEgIS experiment at CERN shoots antihydrogen atoms horizontally - whereupon they fly and fall - at a wall made of matter. On hitting the wall the antihydrogen annihilates with a matter nucleus in the wall to produce a burst of mostly pions and some heavier particles. These particles travel through an emulsion that makes their tracks visible. Tracing these tracks to their point of origin tells the AEgIS team exactly where the annihilation occurred, which in turn allows them to calculate how far each particle travels. AEgIS researchers need volunteers to analyze the images to map the particles' path through the emulsion, and also to classify each track as thick or thin. AntiMatter is being implemented using PyBossa.

Subcontractors are currently developing their applications and are supported with the integration, dissemination and evaluation by the SOCIENTIZE consortium.

\section{DISSEMINATION ACTIVITIES}

Generally, citizen science projects empower citizens, through education and involvement in scientific and decision-making processes, to adopt more active roles in society, while contributing to the production of top-level research. 
The applications promoted by SOCIENTIZE are open to any citizen interested in contributing to the scientific progress. In addition, the consortium aims to recruit specific target groups such as students and teachers through school communities, 50+ people through universities for seniors, and $50+$ platforms, patients associations, and other exclusion groups.

\subsection{Reaching the school community}

It is common for projects fitting the public participation in research model to have both scientific and educational goals. Furthermore, in a formal educational scenario, citizen science projects allow the combination of two important features: use of new technologies and participation in the scientific process. On one hand, students use tools and technologies they relate to such as computers and the Internet. On the other hand, involving the school community in citizen science projects makes the research process more understandable and increases interest among youth for science topics. The direct contact with the scientific process is expected to motivate students to get involved in research and feel that they can make a difference (Lostal, 2013a, 2013b).

In SOCIENTIZE, schools are continuously being recruited, offering teachers the opportunity to enrich science lessons with practical experiences, in particular in what refers to the Cell Spotting application. As described before, different training materials have been prepared for teachers and their students, including a didactic unit and a video explaining the scientific process and research challenges addressed. In the pilot phase of the project (2012/2013), 16 Spanish secondary schools involving nearly 500 students participated (Lostal, 2013a, 2013b). In the school year of 20132014, 50 Spanish schools are using SOCIENTIZE applications in the classroom. Additionally, the Portuguese partners have been working directly with 9 schools, while a broader national campaign to raise awareness for Citizen Science is being set in motion. Activities in schools included workshops for teachers and students. A total of 59 Portuguese teachers from eight schools attended to a Citizen Science workshop where the concept was introduced, applications presented and methods discussed to implement Citizen Science projects in class. 550 students from six schools participated in a workshop specially designed for the application Cell Spotting with a total of 29 sessions. Four videoconferences, with the principal investigator of the Cell Spotting application, were attended by 165 students, and a more general initiative called "Citizen Science Goes to School" was held in two schools which had the participation of more than 150 students. Finally, a contest called "School of Scientists", in a partnership between SOCIENTIZE and the Ibercivis project2, was launched in order to achieve wider attention from the school community. In Brazil, there is an ongoing partnership with a school to also use the Cell Spotting experiment in the classroom. In the beginning of the 2013 school year, the Brazilian partners presented the project and this possibility to approximately 100 teachers, some of which are planning to use citizen science in their classroom in the first semester of 2013. The activities promoted by the consortium have reached around 4000 students, aged 15-18, working with 200 teachers. Furthermore, around 100 students at the University of Hokkaido (Japan) used the Cell Spotting experiment in their Biology class.

\footnotetext{
${ }^{2} \mathrm{http}: / /$ www.ibercivis.net
} 


\subsection{Approaching 50+ people}

Due to the increase of life expectancy and the low levels of fertility, the European population aging is expected to grow in the coming decades. By 2020, it is expected that $20 \%$ of the European population will be composed by people over 65 (COM, 2011). Represented by active and dedicated people willing to be involved and feel useful to others, elderly people are a key group in what concerns the achievement of a better and enhanced society. Thus, citizen science projects can be very attractive for seniors as it increases participants' knowledge, contributes to mental training and active aging and allows participation and contribution to science.

To engage the senior community in the project, SOCIENTIZE established contact with RUTIS Universities of the Third Age Network in Portugal. Around forty 50+ people participated in a workshop called "Citizen Science - To an Active Society in Science" presented in three senior universities. This workshop was designed to introduce the citizen science concept and to explain and demonstrate SOCIENTIZE applications - namely Cell Spotting, Sun4All and Mind Paths. A special "Citizen Science Package" was produced with a brief catch-up on citizen science, citizen science projects and the SOCIENTIZE project and its applications, also with guidelines to help using the applications, the didactic unit for Cell Spotting, and some other promotional materials like brochures and a pin.

First evaluation results of the workshop show a strong interest of participants in the Cell Spotting experiment due to the subject and purpose of the experiment. The majority of respondents think that the active involvement in scientific research is very attractive for $50+$ people as it increases participants' knowledge, contributes to mental training and active aging and allows individuals to contribute to science. These results indicate that $50+$ people are an interesting target group for citizen science projects, especially for those addressing topics of special relevance for older people.

In addition to the initial workshop, the project started to disseminate the Cell Spotting experiment via European 50+ online forums and platforms. Using existing online forums where people 50+ meet and share their experiences and interests, the project introduced the concept of citizen in general and the Cell Spotting experiment more specifically to the 50+ target group. Learning from the direct contact and fruitful discussions with older people on these platforms, the introduction material for the experiment as well as handbooks were further enhanced and adapted to the needs for more guidance of this group of users.

\section{NETWORKING FOR POLICY RECOMMENDATIONS}

The SOCIENTIZE project coordinated public consultation and discussion processes about the potential role of Citizen Science in Europe. The aim of the consultation process was to get a broad understanding of the current status of Citizen Science in Europe by interacting and consulting with a wide range of relevant stakeholders. 
We started the consultation process by performing expert interviews and launching an open call for contributions in order to identify a set of common features and crosscutting concerns among the different institutions, initiatives and models. Those shared issues where mapped and prioritized by identifying key factors and challenges as well as open issues. In different working sessions, including open online consultations, we collected a draft set of general recommendations for Citizen Science in Europe, at strategic and operational levels. As an intermediate result, SOCIENTIZE published a "Green Paper on Citizen Science" in November 2013. This document, entitled "Citizen Science for Europe. Towards a better society of empowered citizens and enhanced research" presents the major themes of discussion and the proposed recommendations and was the basis for more detailed discussions in the course of 2014, leading to the "White Paper on Citizen Science for Europe".

An online consultation platform was set up to present, discuss, update and enhance the initial recommendations stemming from the Green Paper. This process was kicked-off during a workshop organized during the 3rd Citizen Cyberscience Summit in February 2014 in London, which opened formally the period of public consultation and community endorsement. Until April 4, 2014, contributions from about 100 individuals and/or institutions were collected from European and national policy actors, research funders, research institutions, public organizations and institutions, citizen associations, NGOs or others. The results of this online consultation were compiled, further discussed and endorsed in face-to-face workshops and as a result a White Paper was published3 and presented on the September 22, 2014 at the European Conference on Citizen Science held in Brussels. The suggestions for future policies supporting Citizen Science were made on different levels, enabling stakeholders to take concrete actions.

\section{CONCLUSION}

Citizen science presents upfront benefits to different groups of our Society: it provides the scientific community with the means to execute projects that require massive data collection or analysis within a reasonable time period, while it gives volunteers the ability to contribute to the advance of science; to the school community, it opens a direct window into the process of science, facilitating the learning process in the classroom. Finally, for the general society it helps to close the gap between scientists and the public, which may lead to growth in scientific knowledge and active participation in Science.

SOCIENTIZE has implemented a set of applications enabling volunteers to become scientists and showing the capacities of citizens' contributions. Currently, four applications are included in the project portfolio ranging from molecular and cell biology and drug discovery, linguistics and semantics, energy saving and sustainability, astronomy, physics and biodiversity. These applications are open to any citizen interested in contributing to the scientific progress. In addition the consortium is actively addressing a range of different target groups such as students

${ }^{3}$ http://socientize.eu/content/white-paper-citizen-science 
and teachers, 50+ people, patients associations, and other exclusion groups. To support and enrich the experience of the citizens participating in these scientific projects, different training materials have been prepared including didactic units and explanatory videos on the scientific process and research challenges addressed by the different experiments. Around 2,200 registered users contribute regularly to the tasks available for each application running in PyBossa. The validation of the tasks performed by the volunteers is currently based on the replication of the same task to multiple volunteers, and subsequent statistical analysis of the data gathered.

Apart from supporting projects in a wide range of scientific areas, SOCIENTIZE is also concerned with the test and integration of existing technological open source solutions to support the applications deployed. PyBossa and Epiwork are SOCIENTIZE main middleware components for citizen science applications deployment. Additionally, the consortium developed several networking and consultation activities, coordinating all agents involved in Citizen Science in Europe, to create the White Paper on Citizen Science with policy recommendations that were published at the end of September 2014.

\section{ACKNOWLEDGEMENTS}

SOCIENTIZE is a project funded by the European Union Seventh Framework Programme under contract RI-312902. The authors would like to acknowledge the availability and contribution of the principal investigators of the projects for which the applications were developed José Carrodeguas Villar (Cell Spotting), Javier Borges (Mind Paths), José Antonio Turégano (SavingEnergy@Home) and João Fernandes (Sun4All). 


\section{REFERENCES}

Beckage, N., Steyvers, M., \& Butts, C. T. (2011). Route choice in individuals-semantic network navigation. In N. Miyake, D. Peebles, \& R. P. Cooper (Eds.) Proceedings of the 34th Annual Conference of the Cognitive Science Society (pp 108-113). Austin, TX: Cognitive Science Society.

Bonney, R., Cooper, C. B., Dickinson, J., Kelling, S., Phillips, T., Rosenberg, K. V., \& Shirk, J. (2009). Citizen Science: A Developing Tool for Expanding Science Knowledge and Scientific Literacy. BioScience, 59(11), 977984.

Borge-Holthoefer, J., \& Arenas, A. (2010). Categorizing words through semantic memory navigation . Eur. Phys. J. $B, 74,265-270$.

Cohn, J. P. (2008). Citizen Science: Can Volunteers Do Real Research? BioScience, 58(3), $192-197$.

Conesa, C., Doss, M. X., Antzelevitch, C., Sachinidis, A., Sancho, J., \& Carrodeguas, J. A. (2012). Identification of Specific Pluripotent Stem Cell Death- Inducing Small Molecules by Chemical Screening. Stem Cell Reviews and Reports, 8(1), 116-127.

COM - European Commission (2011): Demography Report 2010. Commission staff working document, Luxembourg.

Dickinson, J. L., Zuckerberg, B., \& Bonter, D. N. (2010). Citizen Science as an Ecological Research Tool: Challenges and Benefits. Annual Review of Ecology, Evolution, and Systematics, 41(1), 149-172.

Haklay, M. (2013) Citizen Science and Volunteered Geographic Information - overview and typology of participation. Crowdsourcing Geographic Knowledge: Volunteered Geographic Information (VGI) in Theory and Practice. (pp. 105-122). Ed. Sui, D.Z., Elwood, S. and M.F. Goodchild. Berlin: Springer.

Lostal, E., Serrano, F., Carrodeguas, J. A., Martínez, P., Sanz, F., \& Val, C. (2013a). "Cell Images Analysis as a Case of Citizen Science for Advanced Education: Laboratory and School, Back and Forth". Proceedings of the 7th International Technology, Education and Development Conference (INTED 2013). (pp. 2489-2496). Valencia, Spain, IATED.

Lostal, E., Serrano, F., Carrodeguas, J. A., Martínez, P., Sanz, F., Val, C. (2013b). “A case of Citizen Science for Cell Biology Images Analysis". Proceedings of the XXXIII Congresso da Sociedade Brasileira de Computação (CSBC 2013). (pp. 1855-1862). Maceió, Brazil.

Mueller, M., Tippins, D., \& Bryan, L. (2012). The Future of Citizen Science. Democracy \& Education, 20(1), 1-12.

Quillian, M. R. (1967). Word concepts: A theory and simulation of some basic semantic capabilities. Behavioral Science, 12(5), 410-430.

Quillian, M. R. (1968). Semantic memory. Semantic information processing, 227-270.

Raddick, M. J., Bracey, G., Carney, K., Gyuk, G., Borne, K., Wallin, J., \& Jacoby, S. (2009). Citizen science: status and research directions for the coming decade. Astro2010: The Astronomy and Astrophysics Decadal Survey, Position Papers, no. 46.

Science Communication Unit, University of the West of England, Bristol (2013). Science for Environment Policy Indepth Report: Environmental Citizen Science. Report produced for the European Commission DG Environment, December 2013. Available at: http://ec.europa.eu/science-environment-policy

Shirk, J. L., Ballard, H. L., Wilderman, C. C., Phillips, T., Wiggins, A., Jordan, R., McCallie, E., Minarchek, M., Lewenstein, B. V., Krasny, M. E., \& Bonney., R. (2012). Public participation in scientific research: a framework for deliberate design. Ecology and Society, 17(2), 29.

Wiggins, A., \& Crowston, K. (2010). Developing a conceptual model of virtual organisations for citizen science. International Journal on Organisational Design and Engineering, 1(2), 148-162. 